\title{
Therapeutic effects of conditioned medium from bone marrow-derived mesenchymal stem cells on epithelial-mesenchymal transition in A549 cells
}

\author{
XIN WANG $^{1}$, JUN-LING GAO ${ }^{1-3}$, MAN-MAN ZHAO ${ }^{1}$, HUI-XING ZHU $^{1}$, YAN-XIA TIAN ${ }^{1}$, RAN LI $^{1}$, \\ XIAO-HUA JIANG ${ }^{1}$, LEI YU ${ }^{1}$, JING-RUI TIAN ${ }^{1}$ and JIAN-ZHONG CUI ${ }^{4}$ \\ ${ }^{1}$ School of Basic Medical Sciences, North China University of Science and Technology, Tangshan, Hebei 063210; \\ ${ }^{2}$ Hebei Key Laboratory for Chronic Diseases; ${ }^{3}$ Tangshan Key Laboratory for Preclinical and \\ Basic Research on Chronic Diseases; ${ }^{4}$ Department of Neurosurgery, \\ Tangshan Workers' Hospital, Tangshan, Hebei 063000, P.R. China
}

Received July 28, 2016; Accepted October 4, 2017

DOI: $10.3892 /$ ijmm.2017.3284

\begin{abstract}
Pulmonary fibrosis (PF) is a chronic lung disease. The transforming growth factor- $\beta 1$ (TGF- $\beta 1) / \mathrm{Smad} 3$ signaling pathway plays an important role in the pathogenesis of pulmonary fibrosis. Bone marrow-derived mesenchymal stem cells (BMSCs) have been shown to be a modulator of the molecular aspects of the fibrosis pathway. However, it is still unknown as to whether the conditioned medium from BMSCs (BMSCs-CM) inhibits the epithelial-mesenchymal transition (EMT) process. This study confirmed the hypothesis that BMSCs-CM exerts an anti-fibrotic effect on human type II alveolar epithelial cells (A549) by suppressing the phosphorylation of Smad3. We used the A549 cells in vitro to detect morphological evidence of EMT by phase-contrast microscopy. These cells were randomly divided into 4 groups as follows: the control group, the TGF- $\beta 1$ group, the SIS3 (specific inhibitor of Smad3) group and the BMSCs-CM group. The immunofluorescence method was used to deter-
\end{abstract}

Correspondence to: Dr Jun-Ling Gao, School of Basic Medical Science, North China University of Science and Technology, 21 Bohai Avenue, Caofeidian New Town, Tangshan, Hebei 063210, P.R. China E-mail: junlinggao@163.com

Abbreviations: PF, pulmonary fibrosis; TGF- $\beta 1$, transforming growth factor- $\beta 1$; BMSCs, bone marrow-derived mesenchymal stem cells; EMT, epithelial-mesenchymal transition; E-cad, E-cadherin (E-calcium mucin); $\alpha$-SMA, $\alpha$-smooth muscle actin; CM, conditioned medium; COLI, collagen I, COLIII, collagen III; IL-1RA, interleukin-1 receptor antagonist; DMEM, Dulbecco's modified Eagle's medium; FBS, fetal bovine serum; TEM, transmission electron microscopy; PBS, phosphate-buffered saline; TRITC, tetramethyl rhodamine isothiocyanate; FITC, fluorescein isothiocyanate; DAPI, 4',6-diamidino-2phenylindole; PVDF polyvinylidene fluoride; ECL, chemiluminescence

Key words: bone marrow-derived mesenchymal stem cells, conditioned medium, epithelial-mesenchymal transition, type II alveolar epithelial cells, A549 mined the location of E-cadherin (E-calcium mucins; E-cad), $\alpha$-smooth muscle actin ( $\alpha$-SMA) and $\mathrm{p}$-Smad3. The expression levels of E-cad, CK8, $\alpha$-SMA, vimentin, p-Smad3, Snail1, collagen I (COLI) and collagen III (COLIII) were detected by western blot analysis. Following exposure to TGF- $\beta 1$, the A549 cells displayed a spindle-shaped fibroblast-like morphology. In accordance with these morphological changes, the expression levels of E-cad and CK8 were downregulated, while the expression levels of $\alpha$-SMA and vimentin were upregulated. Along with this process, the expression levels of p-Smad3, Snail1, COLI and COLIII were increased. However, the cells in the BMSCs-CM group and SIS3 group exhibited a decrease in the levels of $\alpha$-SMA and vimentin (which had been upregulated by TGF- $\beta 1$ ), and an increase in the levels of E-cad and CK8 expression (which had been downregulated by TGF- $\beta 1$ ). On the whole, these results indicated that BMSCs-CM suppressed the EMT which might be associated with TGF- $\beta 1 / \mathrm{Smad} 3$. This study provides the theoretical basis for the research of the mechanisms responsible for pulmonary disease.

\section{Introduction}

Pulmonary fibrosis (PF) is a chronic, progressive, irreversible and lethal pulmonary disease, and currently, no effective treatments are available $(1,2)$. There is evidence to indicate that epithelial-mesenchymal transition (EMT) is closely associated with the process of fibrosis (3). EMT involves profound phenotypic changes, including the loss of cell-cell adhesion and cell polarity, and endows cells with a migratory ability and involves the synthesis of the extracellular matrix (4).

Transforming growth factor- $\beta 1$ (TGF- $\beta 1$ ) is a multifunctional cytokine that regulates a wide range of biological phenomena, including tissue morphogenesis, differentiation and extracellular matrix remodeling (5). TGF- $\beta 1$ can effectively induce the conversion of alveolar type II epithelial cells into mesenchymal cells. TGF- $\beta 1$-mediated EMT in several cell types is primarily dependent on the canonical TGF- $\beta 1 / \mathrm{Smad}$ signaling pathway $(6,7)$. Smad proteins are the key molecules in the process of TGF- $\beta 1$ signal transduction, and among these, 
Smad3 is a main substrate of TGF- $\beta 1$ type I receptor kinase and mediates signal transduction in the cell biology $(8,9)$.

Bone marrow-derived mesenchymal stem cells (BMSCs) are pluripotent stem cells derived from bone marrow, with the potential of self-renewal and differentiation into various cell types, such as adipocytes, cardiomyocytes (10), endotheliocytes and neurons (11). BMSCs can perceive damage signals and migrate into the damaged area. BMSCs also have a stronger immune regulatory function, and can avoid immune rejection when in allografts (12). Moreover, it has been demonstrated that BMSCs have anti-inflammatory and regenerative properties (13). In addition, certain studies have indicated that BMSCs can modify the tissue microenvironment and repair the damaged cells via secreting soluable factors. Such soluble factors secreted from BMSCs play a considerable role in terms of the regulation of the immune system, and are associated with anti-inflammatory and anti-fibrotic effects (14-16). Since the transplantation of BMSCs is associated with poor differentiation and survival rates, the utilization of conditioned medium (CM) including trophic factors from BMSCs has emerged as an alternative method $(17,18)$. In a previous study, we demonstrated that BMSCs exhibit anti-fibrotic properties by alleviating the pathological state of silicosis, reducing the inflammatory reaction and suppressing the deposition of collagen. In addition, we also confirmed that BMSCs in lung tissues of rats with silicosis inhibited the expression of tumor necrosis factor (TNF)- $\alpha$ and TGF- $\beta$, and promoted the restoration of lung injury via interleukin-1 receptor antagonist (IL-1RA) (19). However, whether BMSCs-CM can mediate the EMT process, as well as the mechanism involved in this process remain unknown.

In this study, to explore the effect of BMSCs-CM on the development of EMT, we used A549 cells to confirm whether BMSCs-CM can suppress the EMT process. Additionally, to elucidate the possible molecular mechanisms responsible for the protective effect of BMSCs-CM, we examined the levels of E-cadherin (E-calcium mucins; E-cad), CK8, $\alpha$-smooth muscle actin ( $\alpha$-SMA), vimentin, $p$-Smad3, Snail1 and collagen I (COLI) and collagen III (COLIII). This study provides some major theoretical and experimental fundamental principles for BMSCs-CM as a novel therapeutic agent.

\section{Materials and methods}

Culture of BMSCs. All experiments using rats were performed in compliance with the guidelines of the National Institutes of Health Guide for Care and Use of Laboratory Animals. The experimental procedures were approved by the North China University of Science and Technology Experimental Ethics Committee. BMSCs were generated from male Sprague-Dawley (SD) rats $(n=15 ; 3-6$ weeks old; weighing 100-120 g; obtained from Beijing Weitong Lihua, Beijing, China). Rats were anesthetized with an intraperitoneal injection of chloral hydrate (350-400 mg/kg) and were then sacrificed by cervical dislocation. Fresh bone marrow cells were collected by flushing the medullary cavity of rat femurs with Dulbecco's modified Eagle's medium (DMEM; Gibco-BRL, Carlsbad, CA, USA). After filtering, the cells were centrifuged at 1,000 rpm for $5 \mathrm{~min}$. Purified cells were dispersed into cell culture flasks (Corning Life Sciences, Tewksbury, MA, USA), grown in DMEM supplemented with $10 \%$ fetal bovine serum (FBS;
Gibco-BRL), $100 \mathrm{U} / \mathrm{ml}$ penicillin and $100 \mu \mathrm{g} / \mathrm{ml}$ streptomycin (Sigma-Aldrich, St. Louis, MO, USA) and then cultured at $37^{\circ} \mathrm{C}$ with $5 \% \mathrm{CO}_{2}$. After $48 \mathrm{~h}$, non-adherent cells were removed and fresh medium was added. The medium was replaced every 3 days. The adhered cells were allowed to grow to approximately $90 \%$ confluency, and then trypsinized and reseeded. Passage 3 (P3) BMSCs were used for this experiment.

Preparation of BMSCs-CM. After the 3rd generation of BMSCs had adhered to the wall of the flasks for $24 \mathrm{~h}$, they were washed with phosphate-buffered saline (PBS) twice. The cells were then cultured with serum-free DMEM, and the supernatant was collected after $48 \mathrm{~h}$ (cells had reached a confluence of $80 \%$ ). The collected supernatant was then centrifuged at 1,000 rpm for $10 \mathrm{~min}$. After the supernatants were re-centrifuged at 3,000 rpm for $5 \mathrm{~min}$, the $\mathrm{CM}$ was collected with a clean filter to filter to eliminate any bacteria, and then used in the later experiments.

Culture of A549 cells. The A549 cells were obtained from the Chinese Academy of Science Cell Library (TCHu 150, Shanghai, China), and were cultured in DMEM supplemented with 10\% FBS (both from Gibco-BRL) and 1\% antibiotics (penicillin-streptomycin; Sigma-Aldrich) in a humidified $5 \% \mathrm{CO}_{2}$ at $37^{\circ} \mathrm{C}$. The A549 cells were serum-starved for $24 \mathrm{~h}$, and then stimulated with $5 \mathrm{ng} / \mathrm{ml}$ TGF- $\beta 1$ (Peprotech, Rocky Hill, NJ, USA) for $48 \mathrm{~h}$.

Experiment groups. There were 4 experimental groups as follows: i) the control group, in which cells were cultured in serum-free DMEM; ii) the TGF- $\beta 1$ stimulation group (TGF- $\beta 1$ group), in which the cells were cultured in serum-free DMEM and exposed to $5 \mathrm{ng} / \mathrm{ml} \mathrm{TGF-} \beta 1$; iii) the SIS3 inhibitor group (SIS3 group), in which the cells were treated with $3 \mu \mathrm{M}$ SIS3 (specific inhibitor of Smad3) which was added $4 \mathrm{~h}$ prior to $5 \mathrm{ng} / \mathrm{ml} \mathrm{TGF-} \beta 1$ exposure; iv) the BMSCs-CM group (BMSCs-CM group), in which the BMSCs-CM was added prior to $5 \mathrm{ng} / \mathrm{ml}$ TGF- $\beta 1$ exposure. Following incubation for $48 \mathrm{~h}$, the morphology of the cells undergoing EMT was observed under phase-contrast microscope (CKX41; Olympus, Tokyo, Japan).

Observation of cell internal structure by transmission electron microscopy (TEM). The cells were digested with pancreatin and centrifuged at $1,500 \mathrm{rpm}$ for $5 \mathrm{~min}$ at $4^{\circ} \mathrm{C}$. The cells were washed with pre-cooled and sterile PBS, centrifuged under the same conditions and the supernatant was discarded. The sediment was fixed with $2.5 \%$ glutaraldehyde, and then subjected to electron microscopy by first fixin gin $1 \%$ osmic acid, resin embedding and sample preparation, and images were then acquired using a transmission electron microscope (H-7650; Hitachi, Tokyo, Japan).

Transwell migration assay. The migration ability of the cells was evaluated by a Transwell migration chamber assay. The polycarbonate filters ( $8 \mu \mathrm{m}$ pore size) were purchased from Corning Life Sciences. The cells $\left(1 \times 10^{4} /\right.$ insert $)$ that were suspended in $100 \mu 1$ serum-free DMEM were added to the upper chamber, while $600 \mu \mathrm{l}$ of complete medium were added to the lower chamber at $37^{\circ} \mathrm{C}$ in a humidified atmosphere with $5 \% \mathrm{CO}_{2}$. Following incubation for $24 \mathrm{~h}$, the cells that had passed through the polycarbonate filter were stained with crystal violet 
A

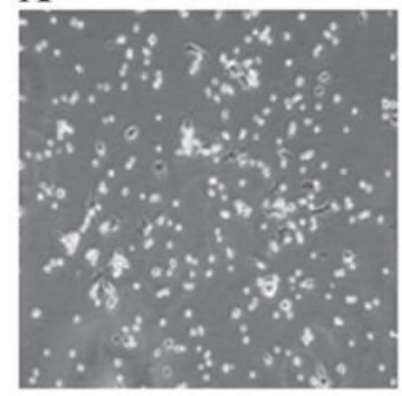

B

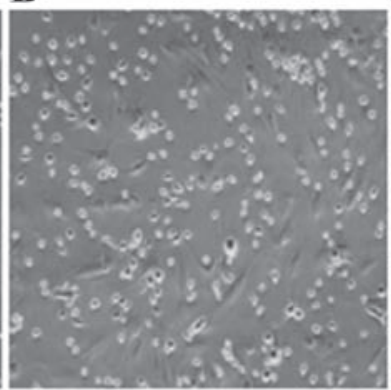

C

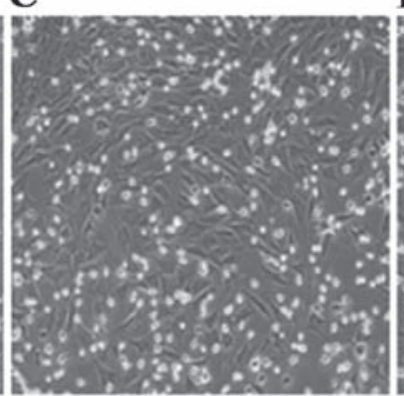

D

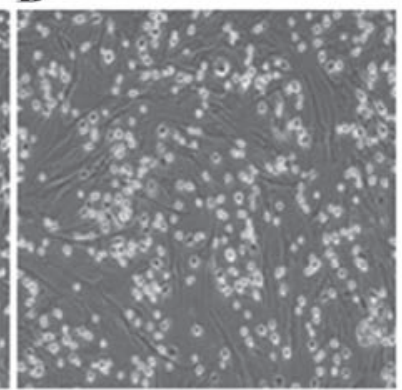

Figure 1. Morphology of BMSCs as observed under an inverted phase contrast microscope (magnification, x200) (A) Primary cells. (B) The first passage BMSCs. (C) The second passage BMSCs. (D) The third passage BMSCs. BMSCs, bone marrow-derived mesenchymal stem cells.

and photographed using an inverted phase contrast microscope. Each migration assay was carried out in triplicate and repeated in 3 independent experiments.

Immunofluorescence analysis. The slides of the cells were fixed in $4 \%$ paraformaldehyde at room temperature for $48 \mathrm{~h}$, and washed 3 times in PBS. The cell samples were permeabilized with $0.4 \%$ Triton X-100 for $30 \mathrm{~min}$ at room temperature, then washed with PBS. Following incubation with blocking solution (5\% normal goat serum) for $1 \mathrm{~h}$, the cells were incubated at $4^{\circ} \mathrm{C}$ overnight with $150 \mu \mathrm{l}$ diluted primary antibody mixture [E-cad (dilution, 1:50; 610181; BD Transduction Laboratories, Franklin Lakes, NJ, USA), $\alpha$-SMA (dilution, 1:1,000; ab32575), p-Smad3 (dilution, 1:100; ab52903; both from Abcam Ltd., Shanghai, China)]. The following day, after being washed with PBS, secondary antibodies labeled with tetramethyl rhodamine isothiocyanate (TRITC; Abcam, Cambridge, MA, USA) and fluorescein isothiocyanate (FITC; BD Transduction Laboratories) were added to each slide and the slides were incubated at room temperature in a wet dark box for $2 \mathrm{~h}$. Then slides were then incubated with 4',6-diamidino2-phenylindole (DAPI; Sigma-Aldrich) for $10 \mathrm{~min}$. Fluorescent images were obtained using a super resolution laser confocal microscope (Leica TCS SP8 STED 3X; serial no. 8100001247; Wetzlar, Germany), and 5 fields from each slide were randomly selected for observation and imaging.

Western blot analysis. The cells were washed with PBS 3 times. RIPA lysis buffer (Aidlab Biotechnologies Co., Ltd., Beijing, China) was added to cover the cell surface, on ice for $30 \mathrm{~min}$. The cells were scraped from the 6-well plates, and collected in an EP tube. The cell suspension was centrifuged at $12,000 \mathrm{x} \mathrm{g}$ for $15 \mathrm{~min}$ at $4^{\circ} \mathrm{C}$ and the supernatant was collected and stored at $-80^{\circ} \mathrm{C}$. The protein concentration of the samples was determined using the BCA reagent (Solarbio, Beijing, China). Proteins from each sample were separated by $10 \%$ sodium dodecyl sulfate-polyacrylamide gel electrophoresis (SDS-PAGE), and then electrotransferred onto polyvinylidene fluoride (PVDF) nitrocellulose membranes (Roche Diagnostics, Mannheim, Germany). The membranes were then incubated with primary antibodies [CK8 (dilution, 1:200; ab59400; Abcam), E-cad (dilution, 1:3,000; 610181; BD Transduction Laboratories), vimentin (dilution, 1:200; ab92547; Epitomics, Burlingame, CA, USA), $\alpha$-SMA (dilution, 1:2,000; ab32575), p-Smad3 (dilution, 1:1,000; ab52903), Snail1 (dilution, 1:200; ab53519;
Anbobio, Shanghai, China), COLI (dilution, 1:500; sc-59772) and COLIII (dilution, 1:500; sc-271249), $\beta$-actin (dilution, 1:500; sc-47778; all from Santa Cruz Biotechnology, Inc., Santa Cruz, CA, USA)], overnight at $4^{\circ} \mathrm{C}$. The following day, the membranes were incubated with secondary antibodies [goat anti-rabbit IgG (dilution, 1:3,000; SA1021) and goat anti-mouse IgG (dilution, 1:3,000; SA1022); both from Wuhan Boster Biotechnology Ltd., Wuhan, China] for $2 \mathrm{~h}$ at $37^{\circ} \mathrm{C}$. The immunoreactive bands were visualized by enhanced chemiluminescence reagent (ECL; Bio-Rad, Hercules, CA, USA). The blots were scanned by densitometry, and the integrated density of pixels was quantified using Image Quant 5.2 software (Molecular Dynamics, Sunnyvale, CA, USA).

Statistical analysis. Statistical analysis was performed using SPSS 17.0 software. Data are presented as the means \pm standard deviation (SD). Each result represents data from at least 3 independent experiments. One-way ANOVA was used to compare overall difference in various groups. A P-value $\leq 0.05$ was considered to indicate a statistically significant difference.

\section{Results}

Morphological observation of BMSCs. The original generation of BMSCs cells gradually adhered following inoculation for $24 \mathrm{~h}$, and had completely adhered within $48 \mathrm{~h}$. The morphological characteristics of the primary cells were circles and polygons, nuclear-centered and occasional polygonal-shaped cells. Cell proliferated mainly in a clone mode. BMSCs were purified by changing the medium several times and during this process, hematopoietic stem cells and other non-adherent growth cells were removed. After 10 days, primary cells which had reached 95\% confluence were passaged. Passaged cells overcame the growth inhibition period and underwent accelerated growth. Following passaging, cell morphology was more uniform and consistent, forming mainly fibroblast-like flattened cells (Fig. 1).

Changes in the morphological characteristics of A549 cells. EMT was significantly promoted in the A549 cells following exposure to $5 \mathrm{ng} / \mathrm{ml} \mathrm{TGF}-\beta 1$ for $48 \mathrm{~h}$. When the cells were pretreated with the BMSCs-CM, EMT was attenuated, as shown in Fig. 2. First, we investigated the morphological changes in A549 cells following their exposure to TGF- $\beta 1$ for $48 \mathrm{~h}$. Inverted phase contrast microscopy revealed that the A549 cells has an epithelial cobblestone-like morphology, a round or polygonal 
Control

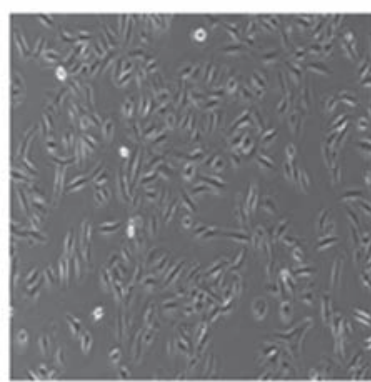

TGF- $\beta 1$

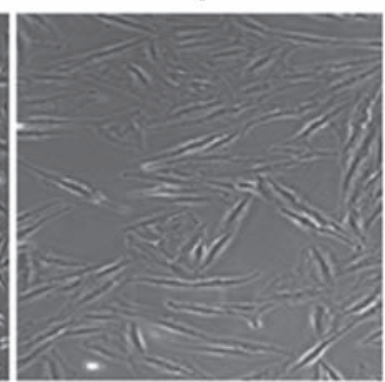

SIS3

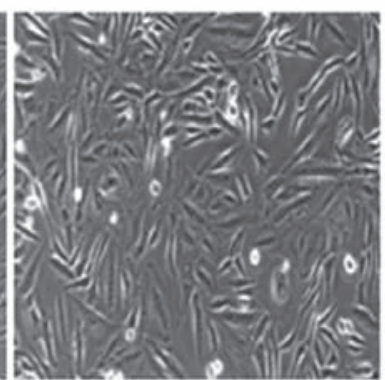

BMSCs-CM

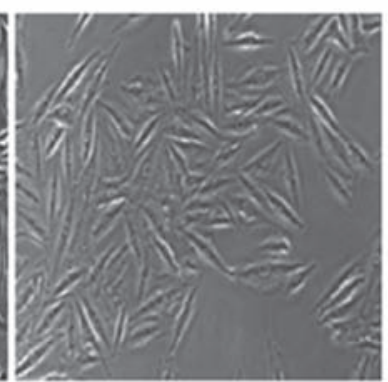

Figure 2. Cell morphology as observed under an inverted phase contrast microscope (magnification, x200). The control group included A549 cells with an epithelial cobblestone-like morphology, a round or polygonal shape. The TGF- $\beta 1$ group included cells that displayed a spindle-shaped elongated fibroblast-like morphology. The cells in the SIS3 group and BMSCs-CM group exhibited a similar morphology; the morphological changes induced by TGF- $\beta 1$ were suppressed The cell groups were as follows: control, cells cultured in serum-free DMEM; TGF- $\beta 1$, cells cultured in serum-free DMEM and exposed to 5 ng/ml TGF- $\beta 1$; SIS3, cells were treated with $3 \mu \mathrm{M}$ SIS3 (specific inhibitor of Smad3) which was added $4 \mathrm{~h}$ prior to $5 \mathrm{ng} / \mathrm{ml}$ TGF- $\beta 1$ exposure; BMSCs-CM, BMSCs-CM was added prior to $5 \mathrm{ng} / \mathrm{ml}$ TGF- $\beta 1$ exposure. BMSCs, bone marrow-derived mesenchymal stem cells; CM, conditioned medium; TGF- $\beta 1$, transforming growth factor- $\beta 1$.
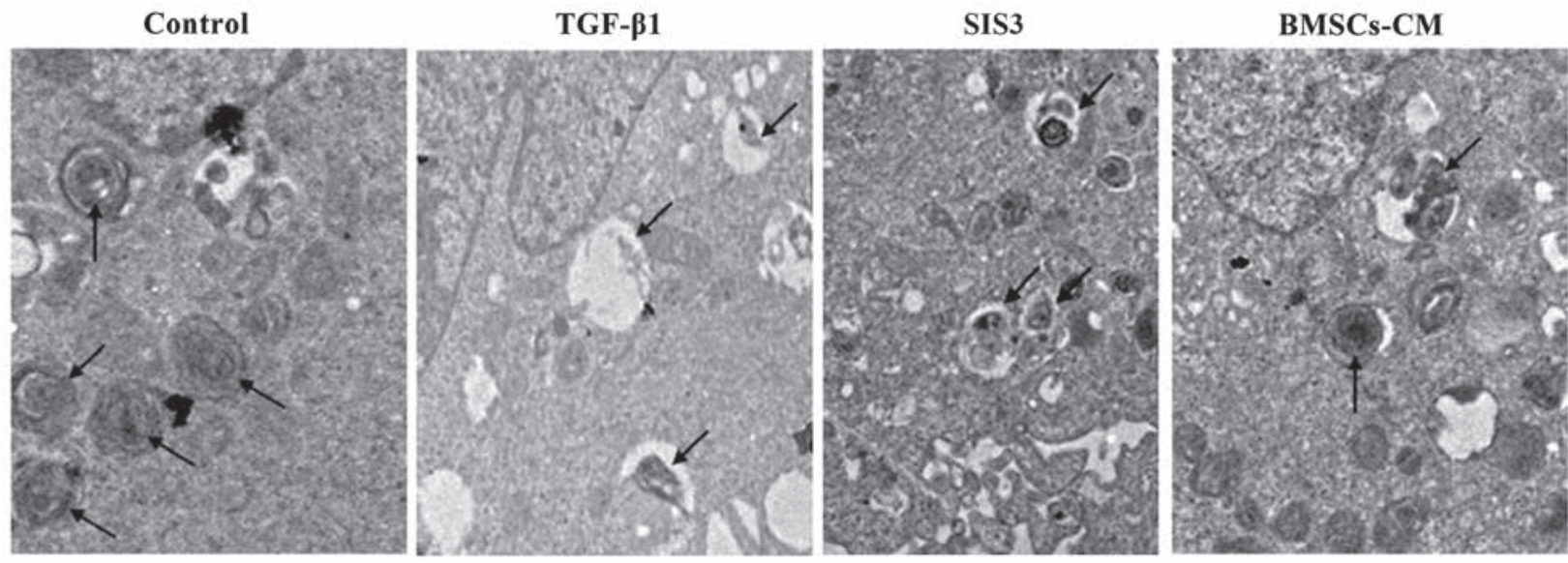

Figure 3. Ultrastructural evidence of EMT. Normal A549 cells can be identified by the presence of LBs in the cytoplasm. In the TGF- $\beta 1$ group, LBs were degeneration, swollen and with vacuoles. Arrows indicate LBs; magnification, x7,000. The cell groups were as follows: control, cells cultured in serum-free DMEM; TGF- $\beta 1$, cells cultured in serum-free DMEM and exposed to $5 \mathrm{ng} / \mathrm{ml}$ TGF- $\beta 1$; SIS3, cells were treated with $3 \mu \mathrm{M}$ SIS3 (specifc inhibitor of Smad3), which was added $4 \mathrm{~h}$ prior to $5 \mathrm{ng} / \mathrm{ml}$ TGF- $\beta 1$ exposure; BMSCs-CM, BMSCs-CM was added prior to $5 \mathrm{ng} / \mathrm{ml}$ TGF- $\beta 1$ exposure. Nu, cell nucleus; LB, lamellar body; EMT, epithelial-mesenchymal transition; TGF- $\beta 1$, transforming growth factor- $\beta 1$.

shape and exhibited very close cell-cell proximity reminiscent of cellular tight-junctions in the control group, while following exposure to TGF- $\beta 1$, the cells displayed a spindle-shaped elongated fibroblast-like morphology. These changes became clearer with the passing of time. These morphological changes became noticeably suppressed in the SIS3 group. Furthermore, the cells in the BMSCs-CM group exhibited similar morphological characteristics as those in the SIS3 grou (Fig. 2).

Changes in the lamellar corpuscle in A549 cells. TEM assay indicated that the characteristics of A549 cell osmiophilic multilamellar body had changed, as evidenced by degeneration, swelling and the formatoin of vacuoles following TGF- $\beta 1$ exposure. However, these phenomena were attenuated in the the SIS3 group and BMSCs-CM group (Fig. 3).

Effects of BMSCs-CM on the migratory ability of A549 cells. As TGF- $\beta 1$ has been reported to induce EMT (20-22), we used it as an experimental system to evaluate the anti-metastatic potential of BMSCs-CM in A549 cells. The migration assay revealed that the migratory ability of the cells exposed to TGF- $\beta 1$ was significantly enhanced compared with that of the cells in the control group. However, the TGF- $\beta 1$-induced enhancement of the cell migratory ability was substantially attenuated in the cells pre-treated with SIS3 or BMSCs-CM compared with the TGF- $\beta 1$ group. Moreover, the migratory ability of the A549 cells in the BMSCs-CM group exhibited no difference when compared with that of the cells in the SIS3 group (Fig. 4).

Effects of BMSCs-CM on the expression of epithelial cell markers and mesenchymal cell markers. To demonstrate the effect of BMSCs-CM on the EMT process in A549 cells, we examined the expression levels of the epithelial cell markers, E-cad and CK8, and the mesenchymal cell markers, vimentin and $\alpha$-SMA, by western blot analysis. As shown in Fig. 5, the results revealed that the expression levels of E-cad and CK8 were significantly decreased, while the expression levels of $\alpha$-SMA and vimentin were increased following exposure to $5 \mathrm{ng} / \mathrm{ml}$ TGF- $\beta 1$ compared with the control group $(\mathrm{P}<0.05)$. By contrast, in the cells in the SIS3 group and the BMSCs-CM group the levels of vimentin and $\alpha$-SMA were decreased, while those of E-cad and CK8 were increased $(\mathrm{P}<0.05)$. 
Control

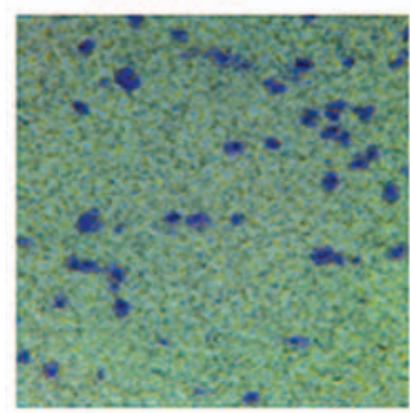

TGF-ß1

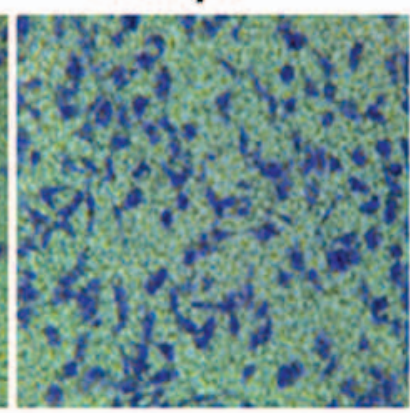

SIS3

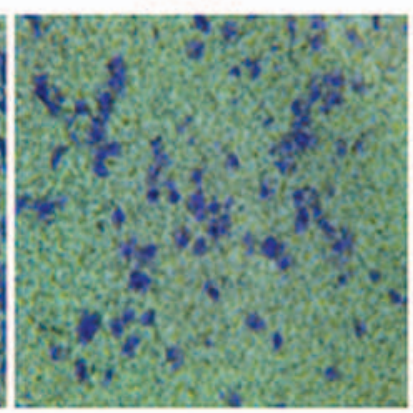

BMSCs-CM

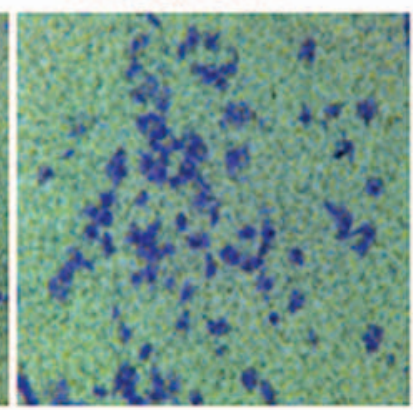

Figure 4. The cell migratory ability observed under an inverted phase contrast microscope during the process of EMT. A549 cells $\left(1 \mathrm{x} 10^{4}\right)$ were seeded on $8 \mu \mathrm{m}$ pore size Transwell chambers and then stimulated with $5 \mathrm{ng} / \mathrm{ml}$ of TGF- $\beta 1$ for $48 \mathrm{~h}$, with or without SIS3 and BMSCs-CM. The cell groups were as follows: control, cells cultured in serum-free DMEM; TGF- $\beta 1$, cells cultured in serum-free DMEM and exposed to 5 ng/ml TGF- $\beta 1$; SIS3, cells were treated with $3 \mu$ M SIS3 (specific inhibitor of Smad3) which was added $4 \mathrm{~h}$ prior to $5 \mathrm{ng} / \mathrm{ml}$ TGF- $\beta 1$ exposure; BMSCs-CM, BMSCs-CM was added prior to $5 \mathrm{ng} / \mathrm{ml}$ TGF- $\beta 1$ exposure. BMSCs, bone marrow-derived mesenchymal stem cells; CM, conditioned medium; EMT, epithelial-mesenchymal transition; TGF- $\beta 1$, transforming growth factor- $\beta 1$.
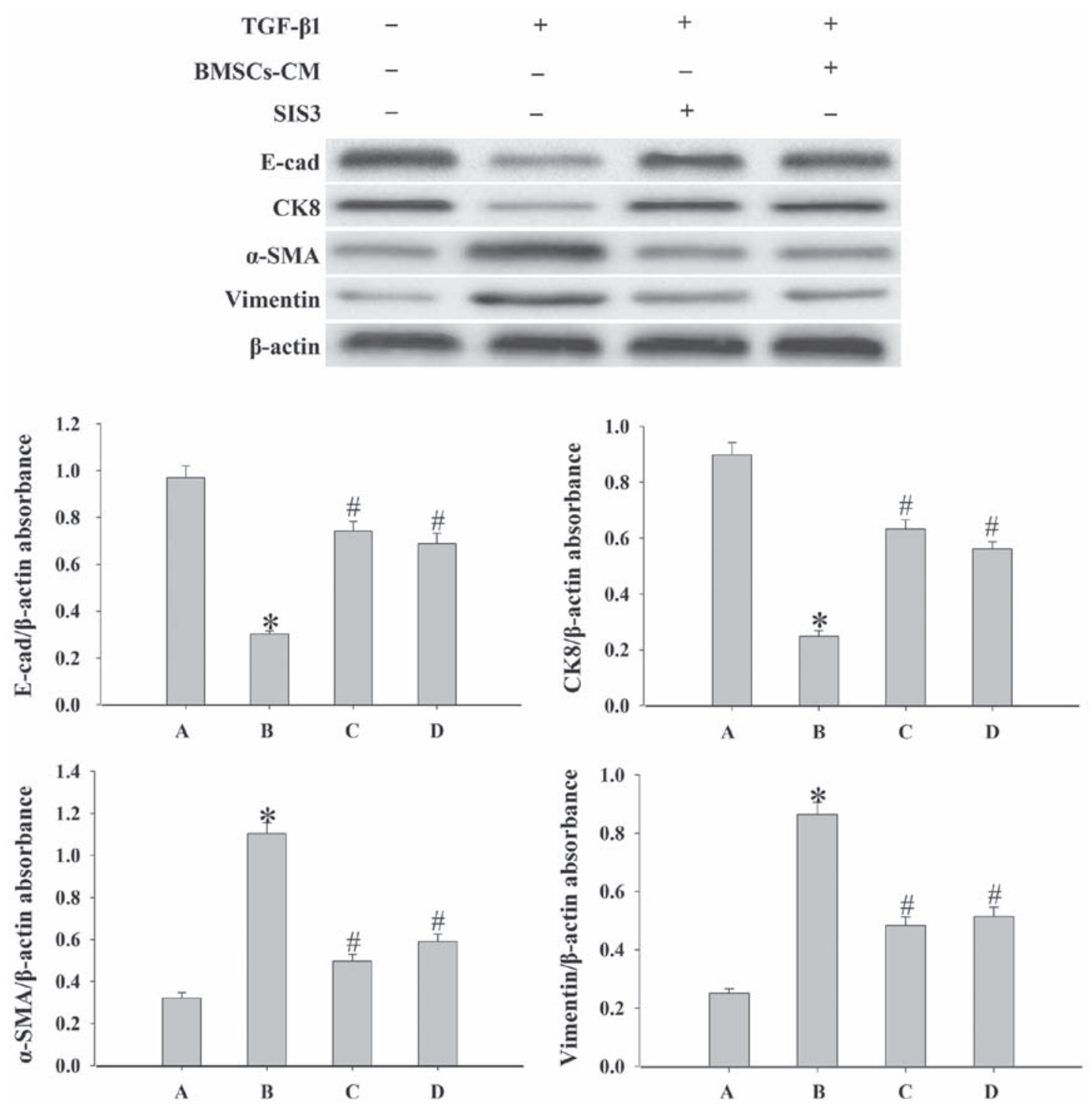

Figure 5. Evaluation of the epithelial cell markers, E-cad and CK8, and the mesenchymal cell markers, $\alpha$-SMA and vimentin, expression in A549 cells. Western blot analysis was used to examine the levels of E-cad, CK8, $\alpha$-SMA and vimentin in the cells. Densitometric analysis of protein expression with $\beta$-actin as the control. The results demonstrated that treatment with BMSCs-CM or SIS3 significantly increased the expression of E-cad and CK8, and decreased $\alpha$-SMA and vimentin protein expression following exposure to TGF- $\beta 1$ ( $\mathrm{P}<0.05$ vs. control group; ${ }^{*} \mathrm{P}<0.05$ vs. TGF- $\beta 1$ group). The bars are labeled as follows: A, control group; B, TGF- $\beta 1$ group; C, SIS3 group; and D, BMSCs-CM group. The cell groups were as follows: control, cells cultured in serum-free DMEM; TGF- $\beta 1$, cells cultured in serum-free DMEM and exposed to $5 \mathrm{ng} / \mathrm{ml}$ TGF- $\beta 1$; SIS3, cells were treated with $3 \mu \mathrm{M}$ SIS3 (specific inhibitor of Smad3) which was added $4 \mathrm{~h}$ prior to $5 \mathrm{ng} / \mathrm{ml}$ TGF- $\beta 1$ exposure; BMSCs-CM, BMSCs-CM was added prior to $5 \mathrm{ng} / \mathrm{ml}$ TGF- $\beta 1$ exposure. BMSCs, bone marrow-derived mesenchymal stem cells; $\mathrm{CM}$, conditioned medium; TGF- $\beta 1$, transforming growth factor- $\beta 1$; E-cad, E-calcium mucins; $\alpha$-SMA, $\alpha$-smooth muscle actin. 


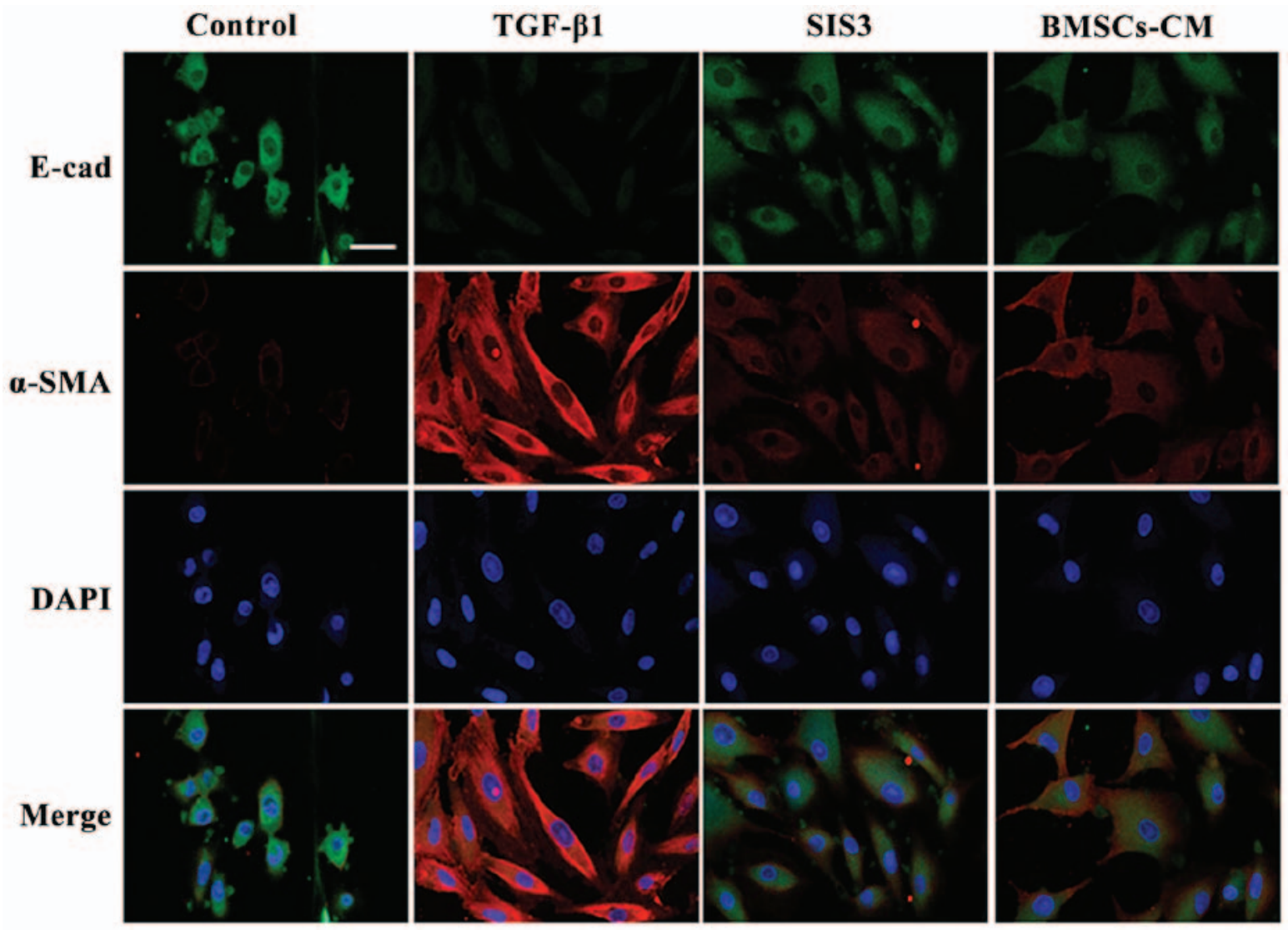

Figure 6. Co-localization of E-cad and $\alpha$-SMA occurs in A549 cells as determined by immunofluorescent staining. E-cad (green) was present in the cytoplasm, FITC-stained; $\alpha$-SMA (red) was present in the cytoplasm, TRITC-stained. Cell nuclei were counterstained with DAPI (blue). Scale bar, $40 \mu \mathrm{m}$. The cell groups were as follows: control, cells cultured in serum-free DMEM; TGF- $\beta 1$, cells cultured in serum-free DMEM and exposed to $5 \mathrm{ng} / \mathrm{ml}$ TGF- $\beta 1$; SIS3, cells were treated with $3 \mu \mathrm{M}$ SIS3 (specific inhibitor of Smad3) which was added $4 \mathrm{~h}$ prior to $5 \mathrm{ng} / \mathrm{ml} \mathrm{TGF-} \beta 1$ exposure; BMSCs-CM, BMSCs-CM was added prior to $5 \mathrm{ng} /$ $\mathrm{ml}$ TGF- $\beta 1$ exposure. E-cad, E-cadherin (E-calcium mucins); $\alpha$-SMA, $\alpha$-smooth muscle actin; TRITC, tetramethyl rhodamine isothiocyanate; FITC, fluorescein isothiocyanate; DAPI, 4',6-diamidino-2-phenylindole.

The results from immunofluorescence assay revealed that E-cad fluorescence expression was decreased in the cell membrane in the TGF- $\beta 1$-exposed cells. By contrast, the expression of E-cad in the cells in the BMSCs-CM group was inhibited to a lesser extent compared with the cells in the TGF- $\beta 1$ group. On the other hand, $\alpha$-SMA fluorescence expression was increased and uniformly distributed in the cytoplasm in the TGF- $\beta 1$-exposed cells. However, the BMSCs-CM reduced the intensity of $\alpha$-SMA fluorescence expression and attenuated the spindle-like morphological changes. The cells in the SIS3 group exhibited similar expression levels of these markers as those in the BMSCs-CM group. These results strongly suggest that BMSCs-CM promote the expression of E-cad and suppress the expression of $\alpha$-SMA (Fig. 6).

BMSCS-CM regulate the EMT process by inhibiting the $T G F-\beta 1 /$ Smad3 signaling pathway. In order to elucidate the mechanisms responsible for the effects of BMSCs-CM on EMT, we examined the expression levels of p-Smad3, Snail1, COLI and COLIII by western blot analysis. SIS3 markedly decreased the expression of $\mathrm{p}-\mathrm{Smad} 3$ that was induced by TGF- $\beta 1$ ( $\mathrm{P}<0.05$; Fig. 7). However, SIS3 did not affect total Smad3 expression. In addition, the results revealed that BMSCs-CM decreased the expression levels of $\mathrm{p}-\mathrm{Smad} 3$ and Snaill $(\mathrm{P}<0.05 ;$ Fig. 7). In addition, the process of EMT induced by TGF- $\beta 1$ was accompanied by an increased expression of COLI and COLIII $(\mathrm{P}<0.05$; Fig. 8). However, when the cells were pre-treated with SIS3 or BMSCs-CM, the expression levels of COLI, COLIII were decreased $(\mathrm{P}<0.05)$.

The results from immunofluorescence assay also indicated that the A549 cells had an obvious nuclear expression of p-Smad3 accompanied by a spindle-shaped-like morphology following TGF- $\beta 1$ exposure. At the same time, the fluorescent expression of p-Smad3 was observed in the cytoplasm. Following pre-treatment with SIS3, the TGF- $\beta 1$-induced morphological changes were not evident and the fluorescence intensity of p-Smad3 was weakened mainly in the nucleus. Furthermore, no significant difference in fluorescence expressions was observed between the BMSCs-CM group and the SIS3 group (Fig. 9).

\section{Discussion}

$\mathrm{PF}$ is a chronic, progressive, irreversible and lethal pulmonary disease, with a poor prognosis and complex pathogenesis. At present, the main aim of PF treatment is to relieve symptoms as much as possible. EMT is a biological process through which epithelial cells undergo a phenotypic transition into mesenchymal cells. This process was initially identified in normal tissue development, such as during embryonic development and 

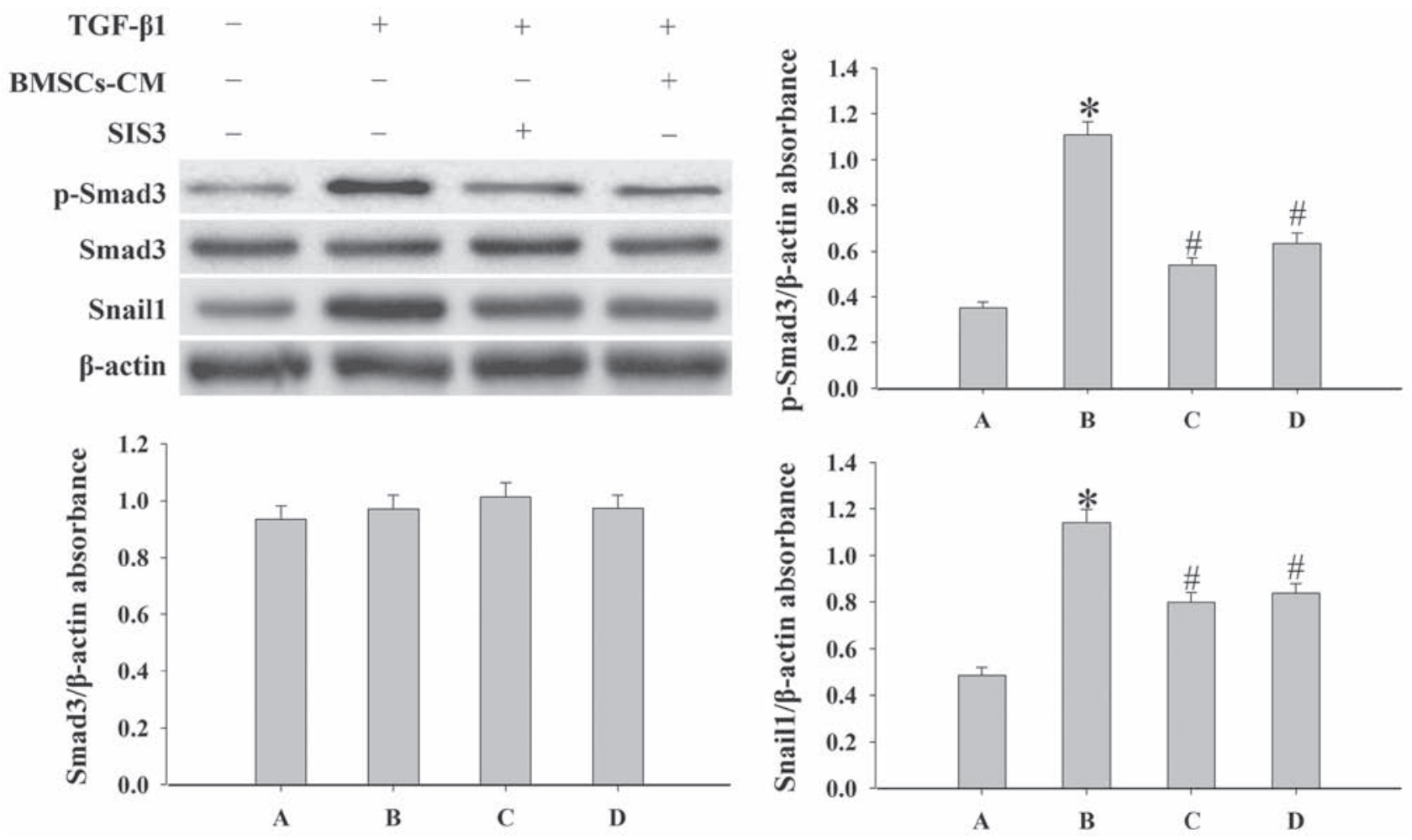

Figure 7. Evaluation of the expression levels of p-Smad3, Smad3 and Snail1 in A549 cells. Western blot analysis was used to examined the levels of p-Smad3, Smad 3 and Snaill in the cells. Densitometric analysis of protein expression with $\beta$-actin as the control. The results demonstrated that treatment with BMSCs-CM or SIS3 significantly decreased the expression of $\mathrm{p}-\mathrm{Smad} 3$ and Snail1 following exposure to TGF- $\beta 1$ (" $\mathrm{P}<0.05$ vs. control group; ${ }^{\#} \mathrm{P}<0.05$ vs. TGF- $\beta 1$ group). The bars are labeled as follows: A, control group; B, TGF- $\beta 1$ group; C, SIS3 group; and D, BMSCs-CM group. The cell groups were as follows: control, cells cultured in serum-free DMEM; TGF- $\beta 1$, cells cultured in serum-free DMEM and exposed to $5 \mathrm{ng} / \mathrm{ml}$ TGF- $\beta 1$; SIS3, cells were treated with $3 \mu$ M SIS3 (specific inhibitor of Smad3) which was added $4 \mathrm{~h}$ prior to $5 \mathrm{ng} / \mathrm{ml}$ TGF- $\beta 1$ exposure. BMSCs-CM, BMSCs-CM was added prior to $5 \mathrm{ng} / \mathrm{ml}$ TGF- $\beta 1$ exposure. BMSCs, bone marrow-derived mesenchymal stem cells; $\mathrm{CM}$, conditioned medium; TGF- $\beta 1$, transforming growth factor- $\beta 1$.

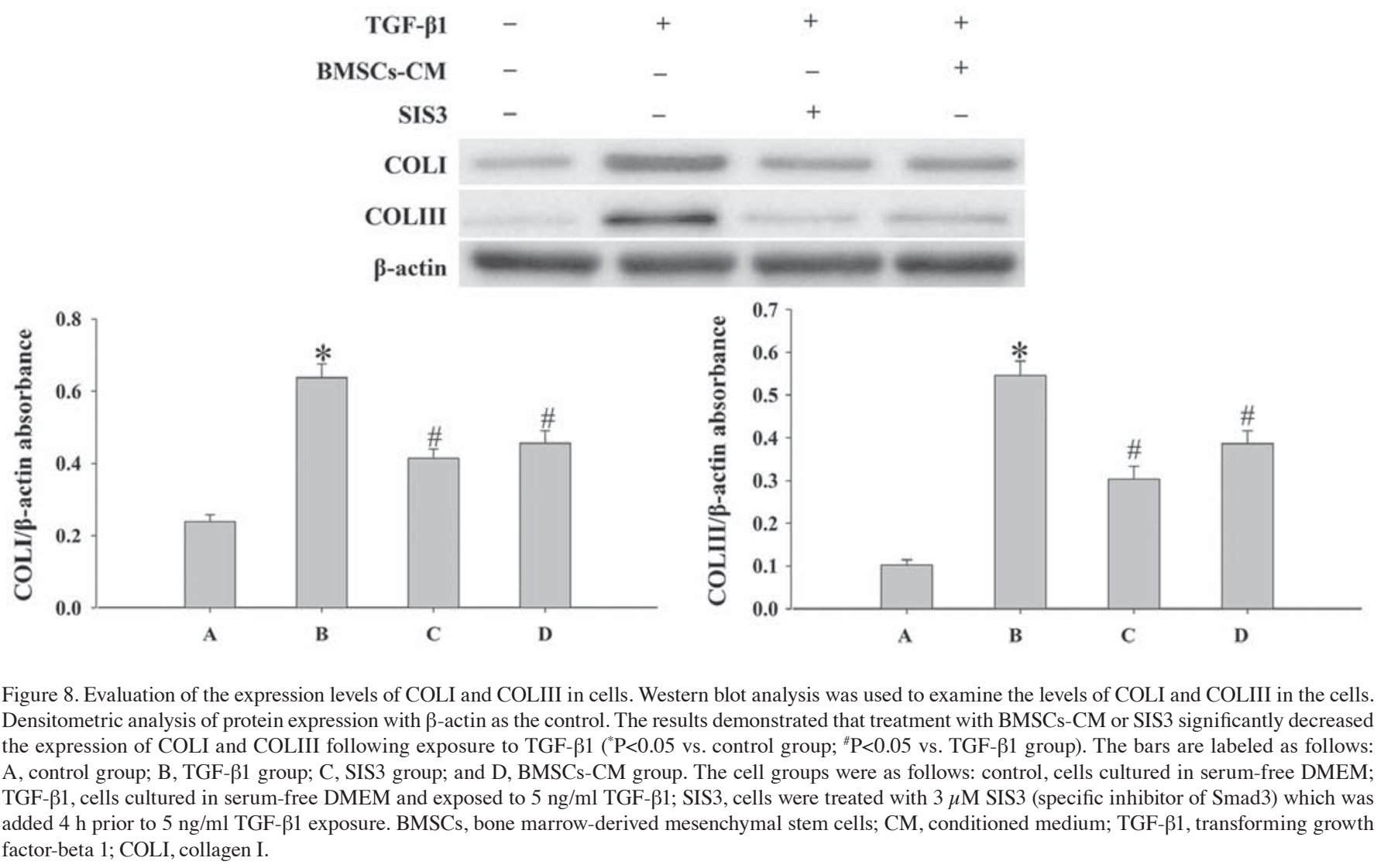




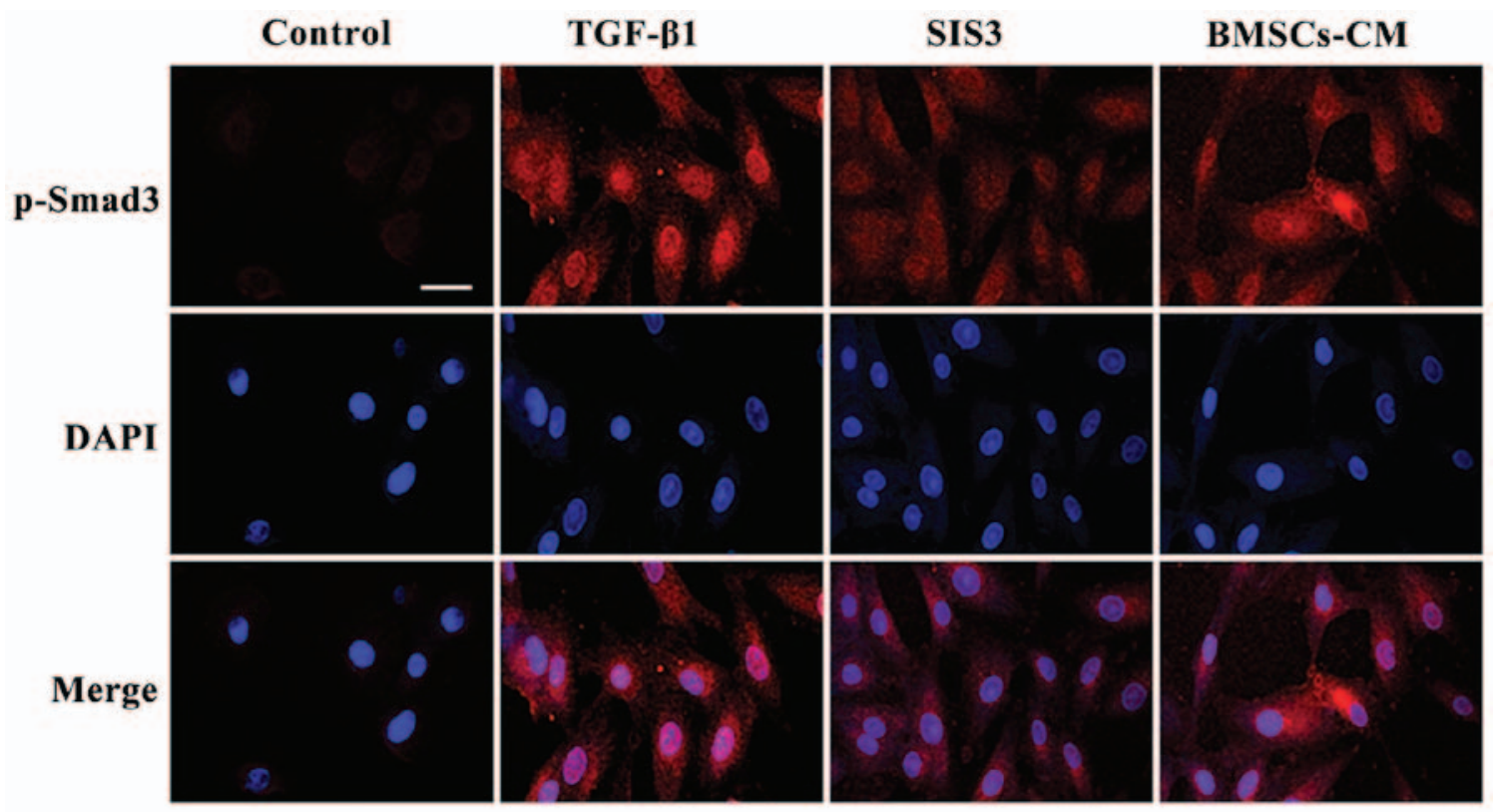

Figure 9. Localization of p-Smad3 occurs in the cells as shown by immunofluorescence. p-Smad3 is shown in red, TRITC-stained; counterstaining of nuclei with DAPI is shown in blue. Scale bar, $50 \mu \mathrm{m}$. The cell groups were as follows: control, cells cultured in serum-free DMEM; TGF- $\beta 1$, cells cultured in serum-free DMEM and exposed to $5 \mathrm{ng} / \mathrm{ml}$ TGF- $\beta 1$; SIS3, cells were treated with $3 \mu \mathrm{M}$ SIS3 (specific inhibitor of Smad3) which was added $4 \mathrm{~h}$ prior to $5 \mathrm{ng} / \mathrm{ml}$ TGF- $\beta 1$ exposure. TRITC, tetramethylrhodamine isothiocyanate; DAPI, 4',6-diamidino-2-phenylindole.

organogenesis (23). Previous studies have suggested that EMT plays an important role in the formation and development of organ fibrosis $(24,25)$. Following TGF- $\beta 1$ exposure in vitro, the morphology of pleural mesothelial cells (MET-5A) has been shown to change from a flat paved stone-like appearance into a spindle-shaped appearance, and this is accompanied by a high $\alpha$-SMA expression and decreased E-cad expression (26). Individual cell motility has been shown to be enhanced in this process, which is a feature of TGF- $\beta 1$-induced EMT (27). In this study, we demonstrated that polygonal A549 cells acquired a spindle-shaped morphology following exposure to TGF- $\beta 1$ for $48 \mathrm{~h}$. Immunofluorescence analysis revealed that the expression of $\alpha$-SMA-positive filaments was increased and the levels of E-cad protein in the cytoplasm were decreased following exposure to TGF- $\beta 1$. Similar results were observed by western blot analysis. Taken together, all these results suggest that TGF- $\beta 1$ successfully induced A549 cell transformation into myofibroblasts.

TGF- $\beta 1$ can be secreted by macrophages, lung epithelial cells and fibroblasts, and is one of the most potent EMT mediators (28-30). The present study demonstrated that TGF- $\beta 1$-mediated EMT was primarily dependent on canonical TGF- $\beta 1 /$ Smad signaling; and canonical TGF- $\beta 1$ signaling has been demonstrated in several cell types $(31,32)$. The signaling of Smad3 is modulated via phosphorylation and cytosolnucleus translocation (33). Smad3 regulates the lung phenotype in pulmonary fibrosis, and the inhibition of $\mathrm{p}-\mathrm{Smad} 3$ can reduce TGF- $\beta 1$-induced EMT and fibrosis $(34,35)$. A number of studies have reported that $\mathrm{Smad} 2 / 3$ are involved in the EMT process (36-39). For example, in hepatic fibrosis, a number of fibrogenic genes (collagens) and markers ( $\alpha$-SMA and E-cad) are Smad3-dependent, and the deletion of Smad3 inhibits COLI expression and blocks EMT (40). In addition, increased $\mathrm{p}-\mathrm{Smad} 2 / 3$ expression was detected during EMT in retinal pigment epithelium cells, which indicated an association between increased $\mathrm{p}-\mathrm{Smad} 2 / 3$ expression and the EMT process (41). Our experimental results revealed that the expression of p-Smad3 was elevated following exposure to TGF- $\beta 1$. This phenomenon was accompanied by a reduction in the levels of epithelial cell markers, while the levels of mesenchymal cell markers and COLI, COLIII were increased. This further supports a role for $\mathrm{p}-\mathrm{Smad} 3$ in the regulation of EMT.

Snail has been known as an essential regulator in TGF- $\beta 1$-induced EMT (42). TGF- $\beta 1$ has been shown to induce Snail expression either through a Smad3-mediated mechanism or through interaction with other signaling pathways, including Ras, Wnt and Notch $(43,44)$. In this study, the resutls of western blot analysis indicated that the expression levels of E-cad were increased, while those of Snaill, $\alpha$-SMA were decreased significantly in the SIS3 group and the BMSCs-CM group. This further confirmed that $\mathrm{p}-\mathrm{Smad} 3$ and Snail1 play an important role in the EMT process.

Studies in vivo have demonstrated the anti-fibrotic properties of BMSCs in the liver (45), kidneys (46) and heart (47), and the application of BMSCs in the treatment of pulmonary fibrosis has gained increasing attention. In vitro, BMSCs can inhibit collagen synthesis and suppress the transdifferentiation of hepatocytes into myofibroblasts (48). Our group has also shown that BMSCs can inhibit silica-induced pulmonary fibrosis and collagen synthesis in vivo (49). However, whether BMSCs-CM is capable of regulating EMT by regulating the TGF- $\beta 1 / \mathrm{p}-\mathrm{Smad} 3$ signaling pathways has not yet been reported, at least to the best of our knowledge. Our present results revealed that treatment of the cells with BMSCs-CM prior to TGF- $\beta 1$ exposure, downregulated the expression of $\mathrm{p}-\mathrm{Smad} 3$, Snail1, $\alpha$-SMA and vimentin, and upregulated the expression levels of E-cad and CK8. This 
confirms that BMSCs-CM suppresses TGF- $\beta 1$-induced EMT via the modulation of p-Smad3, Snail1, COLI and COLIII expression. On the other hand, the migratory ability of the A549 cells was weakened. Similar findings were observed in cells pre-treated with SIS3. Taken together, our results suggest that BMSCs-CM inhibits EMT by modulating p-Smad3 and Snaill expression, thus suppressing pulmonary fibrosis.

In conclusion, the results of this study demonstrate that TGF- $\beta 1 /$ Smad3 signaling is a key pathway in TGF- $\beta 1$-induced EMT. Furthermore, BMSCs-CM can prevent the EMT process, and ameliorate pulmonary fibrosis, which may provided a novel multitarget treatment agent for pulmonary fibrosis.

\section{Acknowledgements}

This study was supported by grants from the Science and Technology Support Key Funding Project of Hebei Province (no. 09276191D); Hebei Province Occupational Disease Prevention and Control Research (no. 13277709D); the Natural Science Foundation of Hebei Province (grant no. H2015209309).

\section{References}

1. Ley B, Collard HR and King TE Jr: Clinical course and prediction of survival in idiopathic pulmonary fibrosis. Am J Respir Crit Care Med 183: 431-440, 2011.

2. Richeldi L, Costabel U, Selman M, Kim DS, Hansell DM, Nicholson AG, Brown KK, Flaherty KR, Noble PW, Raghu G, et al: Efficacy of a tyrosine kinase inhibitor in idiopathic pulmonary fibrosis. N Engl J Med 365: 1079-1087, 2011.

3. Thiery JP, Acloque H, Huang RY and Nieto MA: Epithelialmesenchymal transitions in development and disease. Cell 139: 871-890, 2009

4. Arias AM: Epithelial mesenchymal interactions in cancer and development. Cell 105: 425-431, 2001.

5. Meng XM, Nikolic-Paterson DJ and Lan HY: TGF- $\beta$ : The master regulator of fibrosis. Nat Rev Nephrol 12: 325-338, 2016.

6. Pirozzi G, Tirino V, Camerlingo R, Franco R, La Rocca A, Liguori E, Martucci N, Paino F, Normanno N and Rocco G: Epithelial to mesenchymal transition by TGF $\beta-1$ induction increases stemness characteristics in primary non small cell lung cancer cell line. PLoS One 6: e21548, 2011.

7. Yang G, Liang Y, Zheng T, Song R, Wang J, Shi H, Sun B, Xie C, Li Y, Han J, et al: FCN2 inhibits epithelial-mesenchymal transition-induced metastasis of hepatocellular carcinoma via TGF- $\beta /$ Smad signaling. Cancer Lett 378: 80-86, 2016.

8. Flanders KC: Smad3 as a mediator of the fibrotic response. Int J Exp Pathol 85: 47-64, 2004.

9. Xu F, Liu C, Zhou D and Zhang L: TGF-B/SMAD pathway and its regulation in hepatic fibrosis. J Histochem Cytochem 64: 157-167, 2016.

10. Chen Y, Wang C, Huang Q, Wu D, Cao J, Xu X, Yang C and Li X: Caveolin-1 plays an important role in the differentiation of bone marrow-derived mesenchymal stem cells into cardiomyocytes. Cardiology 136: 40-48, 2017.

11. Nagaya N, Kangawa K, Itoh T, Iwase T, Murakami S, Miyahara Y, Fujii T,Uematsu M, Ohgushi H, Yamagishi M, et al: Transplantation of mesenchymal stem cells improves cardiac function in a rat model of dilated cardiomyopathy. Circulation 112: 1128-1135, 2005.

12. Mezey E: The therapeutic potential of bone marrow-derived stromal cells. J Cell Biochem 112: 2683-2687, 2011.

13. Oh JY, Kim MK, Shin MS, Lee HJ, Ko JH, Wee WR and Lee JH: The anti-inflammatory and anti-angiogenic role of mesenchymal stem cells in corneal wound healing following chemical injury. Stem Cells 26: 1047-1055, 2008.

14. Shi M, Liu ZW and Wang FS: Immunomodulatory properties and therapeutic application of mesenchymal stem cells. Clin Exp Immunol 164: 1-8, 2011.

15. Chiesa S, Morbelli S, Morando S, Massollo M, Marini C, Bertoni A, Frassoni F, Bartolomé ST, Sambuceti G, Traggiai E, et al: Mesenchymal stem cells impair in vivo T-cell priming by dendritic cells. Proc Natl Acad Sci USA 108: 17384-17389, 2011.
16. Suganuma S, Tada K, Hayashi K, Takeuchi A, Sugimoto N, Ikeda $\mathrm{K}$ and Tsuchiya $\mathrm{H}$ : Uncultured adipose-derived regenerative cells promote peripheral nerve regeneration. J Orthop Sci 18: 145-151, 2013.

17. Chen L, Tredget EE, Wu PY and Wu Y: Paracrine factors of mesenchymal stem cells recruit macrophages and endothelial lineage cells and enhance wound healing. PLoS One 3: e1886, 2008.

18. Li X, Luo Q, Sun J and Song G: Conditioned medium from mesenchymal stem cells enhances the migration of hepatoma cells through CXCR4 upregulation and F-actin remodeling. Biotechnol Lett 37: 511-521, 2015.

19. Zhao MM, Cui JZ, Cui Y, Li R, Tian YX, Song SX, Zhang J and Gao JL: Therapeutic effect of exogenous bone marrow derived mesenchymal stem cell transplantation on silicosis via paracrine mechanisms in rats. Mol Med Rep 8: 741-746, 2013.

20. Watanabe-Takano H, Takano K, Hatano M, Tokuhisa T and Endo T: DA-Raf-mediated suppression of the Ras-ERK pathway is essential for TGF- $\beta 1$-induced epithelial-mesenchymal transition in alveolar epithelial type 2 cells. PloS One 10: e0127888, 2015.

21. Yeh YC, Wei WC, Wang YK, Lin SC, Sung JM and Tang MJ: Transforming growth factor- $\{$ beta 1 induces Smad3-dependent \{beta\}1 integrin gene expression in epithelial-to-mesenchymal transition during chronic tubulointerstitial fibrosis. Am J Pathol 177: 1743-1754, 2010.

22. Willis BC and Borok Z: TGF-beta-induced EMT: mechanisms and implications for fibrotic lung disease. Am J Physiol Lung Cell Mol Physiol 293: L525-L534, 2007.

23. Thiery JP: Epithelial-mesenchymal transitions in cancer onset and progression. Bull Acad Natl Med 193: 1969-1979, 2009 (In French)

24. Carew RM, Wang B and Kantharidis P: The role of EMT in renal fibrosis. Cell Tissue Res 347: 103-116, 2012.

25. Hosper NA, van den Berg PP, de Rond S, Popa ER, Wilmer MJ, Masereeuw R and Bank RA: Epithelial-to-mesenchymal transition in fibrosis: Collagen type I expression is highly upregulated after EMT, but does not contribute to collagen deposition. Exp Cell Res 319: 3000-3009, 2013.

26. Wettstein G, Bellaye PS, Kolb M, Hammann A, Crestani B, Soler P, Marchal-Somme J, Hazoume A, Gauldie J, Gunther A, et al: Inhibition of HSP27 blocks fibrosis development and EMT features by promoting Snail degradation. FASEB J 27: 1549-1560, 2013.

27. Perez RE, Navarro A, Rezaiekhaligh MH, Mabry SM and Ekekezie II: TRIP-1 regulates TGF- $\beta 1$-induced epithelialmesenchymal transition of human lung epithelial cell line A549. Am J Physiol Lung Cell Mol Physiol 300: L799-L807, 2011.

28. He X, Young SH, Schwegler-Berry D, Chisholm WP, Fernback JE and Ma Q: Multiwalled carbon nanotubes induce a fibrogenic response by stimulating reactive oxygen species production, activating NF- $\mathrm{KB}$ signaling, and promoting fibroblast-tomyofibroblast transformation. Chem Res Toxicol 24: 2237-2248, 2011.

29. Aschner $Y$ and Downey GP: Transforming growth factor- $\beta$ : Master regulator of the respiratory system in health and disease. Am J Respir Cell Mol Biol 54: 647-655, 2016.

30. Tamminen JA, Myllärniemi M, Hyytiäinen M, Keski-Oja J and Koli K: Asbestos exposure induces alveolar epithelial cell plasticity through MAPK/Erk signaling. J Cell Biochem 113: 2234-2247, 2012.

31. Zhang YE: Non-Smad pathways in TGF- $\beta$ signaling. Cell Res 19: 128-139, 2009

32. Reyes-Reyes EM, Ramos IN, Tavera-Garcia MA and Ramos KS: The aryl hydrocarbon receptor agonist benzo(a)pyrene reactivates LINE-1 in HepG2 cells through canonical TGF- $\beta 1$ signaling: Implications in hepatocellular carcinogenesis. Am J Cancer Res 6: 1066-1077, 2016.

33. Derynck R and Zhang YE: Smad-dependent and Smadindependent pathways in TGF- $\beta$ family signalling. Nature 425 : 577-584, 2003.

34. Wang C, Song X, Li Y, Han F, Gao S, Wang X, Xie S and Lv C: Low-dose paclitaxel ameliorates pulmonary fibrosis by suppressing TGF- $\beta 1 / \mathrm{Smad} 3$ pathway via miR-140 upregulation. PLoS One 8: e70725, 2013.

35. Xie L, Zhou D, Xiong J, You J, Zeng Y and Peng L: Paraquat induce pulmonary epithelial-mesenchymal transition through transforming growth factor- $\beta 1$-dependent mechanism. Exp Toxicol Pathol 68: 69-76, 2016. 
36. Liu L, Wang Y, Yan R, Li S, Shi M, Xiao Y and Guo B: Oxymatrine inhibits renal tubular EMT induced by high glucose via upregulation of SnoN and inhibition of TGF- $\beta 1 / \mathrm{Smad}$ signaling pathway. PLoS One 11: e0151986, 2016.

37. Dong Z, Tai W, Lei W, Wang Y, Li Z and Zhang T: IL-27 inhibits the TGF- $\beta 1$-induced epithelial-mesenchymal transition in alveolar epithelial cells. BMC Cell Biol 17: 7, 2016.

38. Zhang L, Cheng X, Gao Y, Zhang C, Bao J, Guan H, Yu H, Lu R, Xu Q and Sun Y: Curcumin inhibits metastasis in human papillary thyroid carcinoma BCPAP cells via downregulation of the TGF- $\beta /$ Smad2/3 signaling pathway. Exp Cell Res 341: $157-165,2016$.

39. Kong D, Zhang F, Shao J, Wu L, Zhang X, Chen L, Lu Y and Zheng S: Curcumin inhibits cobalt chloride-induced epithelialto-mesenchymal transition associated with interference with TGF- $\beta /$ Smad signaling in hepatocytes. Lab Invest 95: 1234-1245, 2015.

40. Masszi A and Kapus A: Smaddening complexity: The role of Smad3 in epithelial-myofibroblast transition. Cells Tissues Organs 193: 41-52, 2011.

41. Chen Z, Mei Y, Lei H, Tian R, Ni N, Han F, Gan S and Sun S: LYTAK1, a TAK 1 inhibitor, suppresses proliferation and epithelial mesenchymal transition in retinal pigment epithelium cells. Mol Med Rep 14: 145-150, 2016.

42. Smith KA, Zhou B, Avdulov S, Benyumov A, Peterson M, Liu Y, Okon A, Hergert P, Braziunas J, Wagner CR, et al: Transforming growth factor- $\beta 1$ induced epithelial mesenchymal transition is blocked by a chemical antagonist of translation factor eIF4E. Sci Rep 5: 18233, 2015.
43. Xu J, Lamouille S and Derynck R: TGF-beta-induced epithelial to mesenchymal transition. Cell Res 19: 156-172, 2009.

44. Zavadil J, Cermak L, Soto-Nieves N and Böttinger EP: Integration of TGF-beta/Smad and Jagged1/Notch signalling in epithelialto-mesenchymal transition. EMBO J 23: 1155-1165, 2004.

45. Wang ZC, Yang S, Huang JJ, Chen SL, Li QQ and Li Y: Effect of bone marrow mesenchymal stem cells on the Smad expression of hepatic fibrosis rats. Asian Pac J Trop Med 7: 321-324, 2014.

46. Lang $\mathrm{H}$ and Dai C: Effects of bone marrow mesenchymal stem cells on plasminogen activator inhibitor-1 and renal fibrosis in rats with diabetic nephropathy. Arch Med Res 47: 71-77, 2016.

47. Cai B, Tan X, Zhang Y, Li X, Wang X, Zhu J, Wang Y, Yang F, Wang B, Liu Y, et al: Mesenchymal stem cells and cardiomyocytes interplay to prevent myocardial hypertrophy. Stem Cells Transl Med 4: 1425-1435, 2015.

48. Jang YO, Kim MY, Cho MY, Baik SK, Cho YZ and Kwon SO: Effect of bone marrow-derived mesenchymal stem cells on hepatic fibrosis in a thioacetamide-induced cirrhotic rat model. BMC Gastroenterol 14: 198, 2014.

49. Zhao MM, Cui JZ, Li R, Du LJ, Tian YX, Kan Q, Zhang J and Gao JL: Effects of bone mesenchymal stem cell transplantation on silicosis fibrosis in rats. Chin J Pathophysiol 28: 2205-2210, 2012.

This work is licensed under a Creative Commons Attribution-NonCommercial-NoDerivatives 4.0 International (CC BY-NC-ND 4.0) License. 